Civil Engineering

Volume 170 Issue CE5

Crossrail project: machine-driven tunnels on the Elizabeth line, London King, Thomas and Stenning
Proceedings of the Institution of Civil Engineers Civil Engineering 170 May 2017 Issue CE5 Pages 31-38 http://dx.doi.org/10.1680/jcien. 16.00028 Paper 1600028

Received 11/07/2016 Accepted 16/12/2016 Keywords: concrete structures/excavation/tunnels \& tunnelling i ice Institution of Civil Engineers

\title{
Crossrail project: machine-driven tunnels on the Elizabeth line, London
}

1 Mike King BSC, CEng, MICE Technical and Compliance Director - Tunnels, CH2M, London, UK

2 Ivor Thomas BEng, LLB, CEng, FICE Tunnel Manager, BAM Nuttall, London, UK
3 Andy Stenning BSC, PhD, CPEng, MIEAust, MHKIE, MASCE Technical Director, Atkins Ltd, London, UK
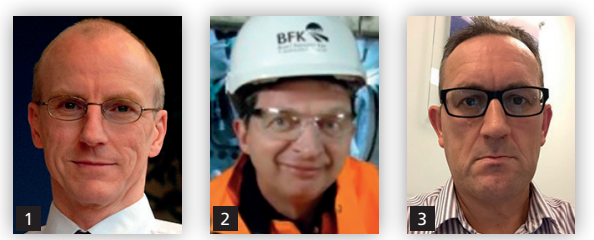

The $42 \mathrm{~km}$ of tunnels constructed using soft-ground pressure-balance tunnel-boring machines for London's new Elizabeth line were completed over a 3 year period. A single lining design solution was developed for all tunnels using a fully gasketed, steel-fibre-reinforced, concrete segmental lining suitable for use in all potential ground conditions anticipated along the alignment. The $\mathbf{f 1 4 . 8}$ billion Crossrail project faced many challenges, including dealing with significant quantities of different excavated material while minimising the environmental impact from transportation and disposal, minimising settlement effects and dealing with multiple tunnel-boring machine launches and receptions. This paper addresses how the issues were tackled and comments on the tunnel-boring machine design and the approach taken for survey control. Outline figures are also provided for the tunnelling rates. Finally, some conclusions and recommendations are made based on the observations and lessons learnt during the project.

\section{Introduction}

The $£ 14.8$ billion Crossrail project to deliver the $118 \mathrm{~km}$ Elizabeth line across London, UK, required $21 \mathrm{~km}$ of twin running tunnels in the central part of the route (Tucker, 2017). They were constructed using a total of eight tunnel-boring machines (TBMs) working in five sets of parallel tunnel drives, as shown in Figure 1.

Pressure-balance TBMs were adopted across the whole project to deal with the ground and groundwater conditions anticipated, and to control ground movements under sensitive structures and close to underground assets, including existing operational metro lines and old utilities sensitive to disturbance.

Of the eight TBMs, six were earth-pressure-balance machines (EPBMs) and two were slurry shield machines, which were for use in the water-bearing Chalk aquifer. The drives were let in three main tunnel contracts, with details as shown in Table 1.

Tunnel construction extended over a 3 year period, with the final TBM on drive $\mathrm{Y}$ arriving at Farringdon station in May 2015.

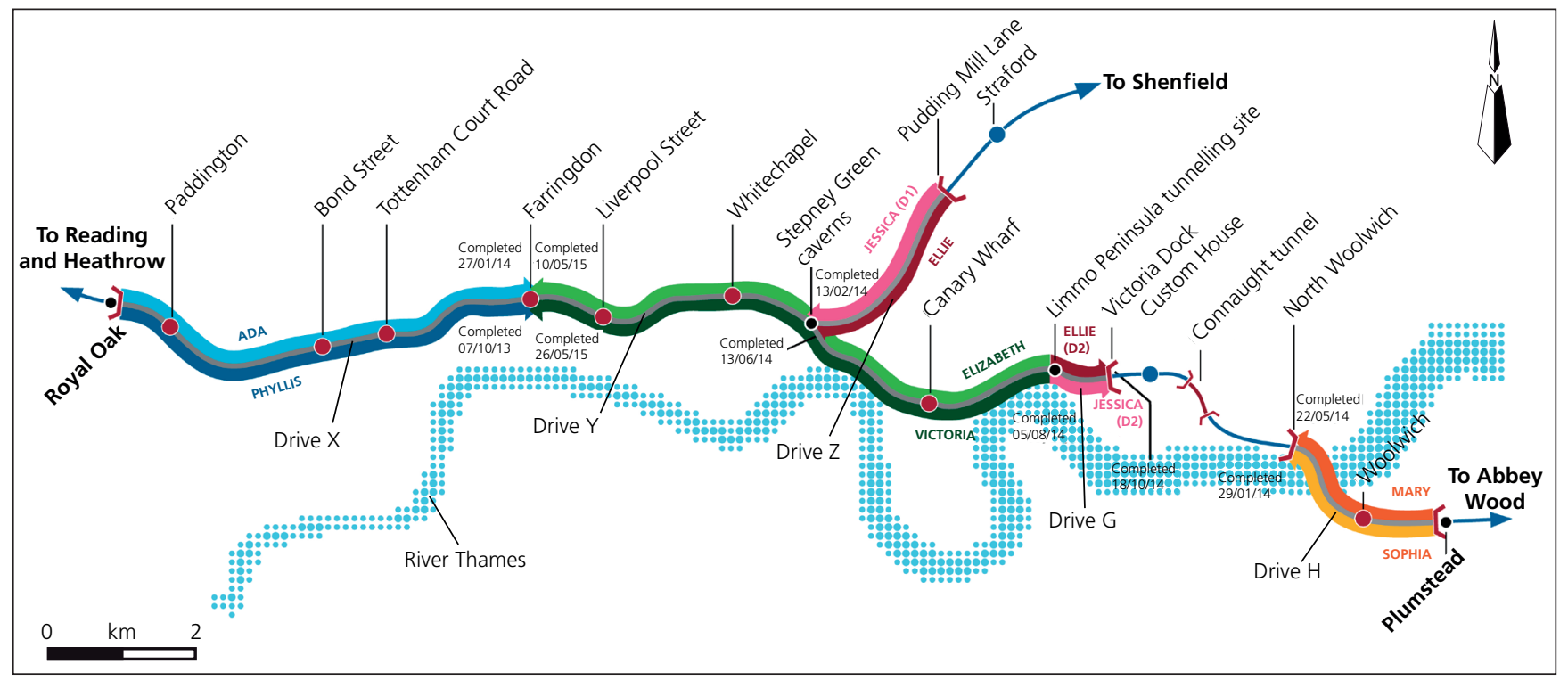

Figure 1. Plan of central tunnelled section showing TBM drives 
Table 1. TBM contract details

\begin{tabular}{lllll} 
Contract & Drive & Location & TBM type & Length: km \\
\hline C300 & X & Royal Oak to Farringdon & Earth pressure balance & $6 \cdot 8$ \\
C305 & Y & Limmo to Farringdon & Earth pressure balance & $7 \cdot 9$ \\
& Z & Pudding Mill Lane to Stepney Green & Earth pressure balance & $2 \cdot 7$ \\
& G & Limmo to Victoria Dock & Earth pressure balance & 0.9 \\
\hline C310 & H & Plumstead to North Woolwich & Slurry & $2 \cdot 8$ \\
\hline
\end{tabular}

\section{Ground conditions}

The typical geological sequence under London, and the general description of the strata encountered along the route, are shown in Table 2 (Black, 2017). The main strata encountered by the TBMs along each drive length are summarised below, with descriptions given in the direction of TBM drive, and shown in Figure 2.

In drive $\mathrm{X}$, from the Royal Oak portal, the tunnels were launched in River Terrace Deposits before moving into the London Clay, continuing in this stratum as far as the Fisher Street crossover, where the Soho anticline brings Palaeocene strata closer to the surface. Here the tunnel alignment dropped into the Lambeth Group clays and sands. The tunnels just entered the lower Lambeth Group sands, gravels and silts as they progressed into Farringdon station.

On drive Y, at Limmo shaft the tunnels started in London Clay but quickly passed through the Lambeth Group upper and lower units before partially entering the Thanet Sands. The tunnels followed the lower Lambeth Group/Thanet Sand boundary until the Stepney Green area, where the tunnels moved back into the London Clay, and in which they remained until part way between Whitechapel and Liverpool Street stations. At this point the tunnel alignment descended and they continued with mixed face conditions of London Clay and Lambeth Group up to the east end of Farringdon station where the drive terminated and the machines were dismantled.

Drive $\mathrm{Z}$ started at the Pudding Mill Lane portal. The TBMs launched at the interface between the London Clay and the
Lambeth Group with the face mainly in the clay. The alignment dropped the tunnels into the Lambeth Group before rising again into the London Clay, where they remained until the tunnels completed their drive at Stepney Green.

Drive $G$ was launched from Limmo shaft in London Clay. The TBMs remained in the clay with only occasional Lambeth Group strata in the invert until arriving at Victoria Dock portal where the crown of the tunnels intersected treated layers of River Terrace Deposits.

The drive $\mathrm{H}$ TBMs launched in Plumstead at the interface between the Thanet Sand and the Chalk, dropping down into the Chalk for the majority of the route, only rising into the Thanet Sands either side of Woolwich station. As the tunnels ascended to the reception point at North Woolwich portal, the face was again moving partially into the River Terrace Deposits.

\section{Health, safety and welfare}

Analysis of all incidents, near misses and accidents during the Crossrail tunnelling drives provides a breakdown of risk type as shown in Figure 3.

Occupational health nurses were provided by the contractors at all tunnelling sites and proved their worth time and time again.

Shift patterns varied, with most of the contractors working two $12 \mathrm{~h}$ shifts a day in a seven day week, the exception being in the west where the contractor chose to work three $8 \mathrm{~h}$ shifts a day.

Table 2. Ground conditions on route alignment

\begin{tabular}{|ll}
\hline Strata & Typical description \\
\hline Made ground & Variable \\
\hline Alluvium & Soft to firm, sandy, slightly gravelly, organic silty clay \\
\hline River Terrace Deposits & $\begin{array}{l}\text { Medium-dense fine to coarse sand and gravel with rare cobbles and flints. Perched water table above } \\
\text { London Clay }\end{array}$ \\
\hline London Clay & $\begin{array}{l}\text { Firm to very stiff fissured clay with silt partings and laminations. Considered an aquitard not } \\
\text { containing significant quantities of groundwater }\end{array}$ \\
\hline Lambeth Group & $\begin{array}{l}\text { Variable sub-strata varying from stiff to hard (possibly friable), closely fissured, sandy to very sandy } \\
\text { clay, to stiff to very stiff silty to very silty clay. The Upnor Formation at the base of the Group varies } \\
\text { from very stiff sandy silty clay to very dense clayey silty fine to coarse sand. Lower clay content layers } \\
\text { are associated with higher permeability and connectivity with lower water-bearing layers }\end{array}$ \\
\hline Thanet Sand & $\begin{array}{l}\text { Very dense, silty, fine and medium sand. Highly permeable and in hydraulic connectivity with } \\
\text { underlying chalk }\end{array}$ \\
\hline Chalk & $\begin{array}{l}\text { Medium density, weak to moderately weak, fractured chalk with flint bands. Contains large } \\
\text { quantities of water }\end{array}$ \\
\hline
\end{tabular}




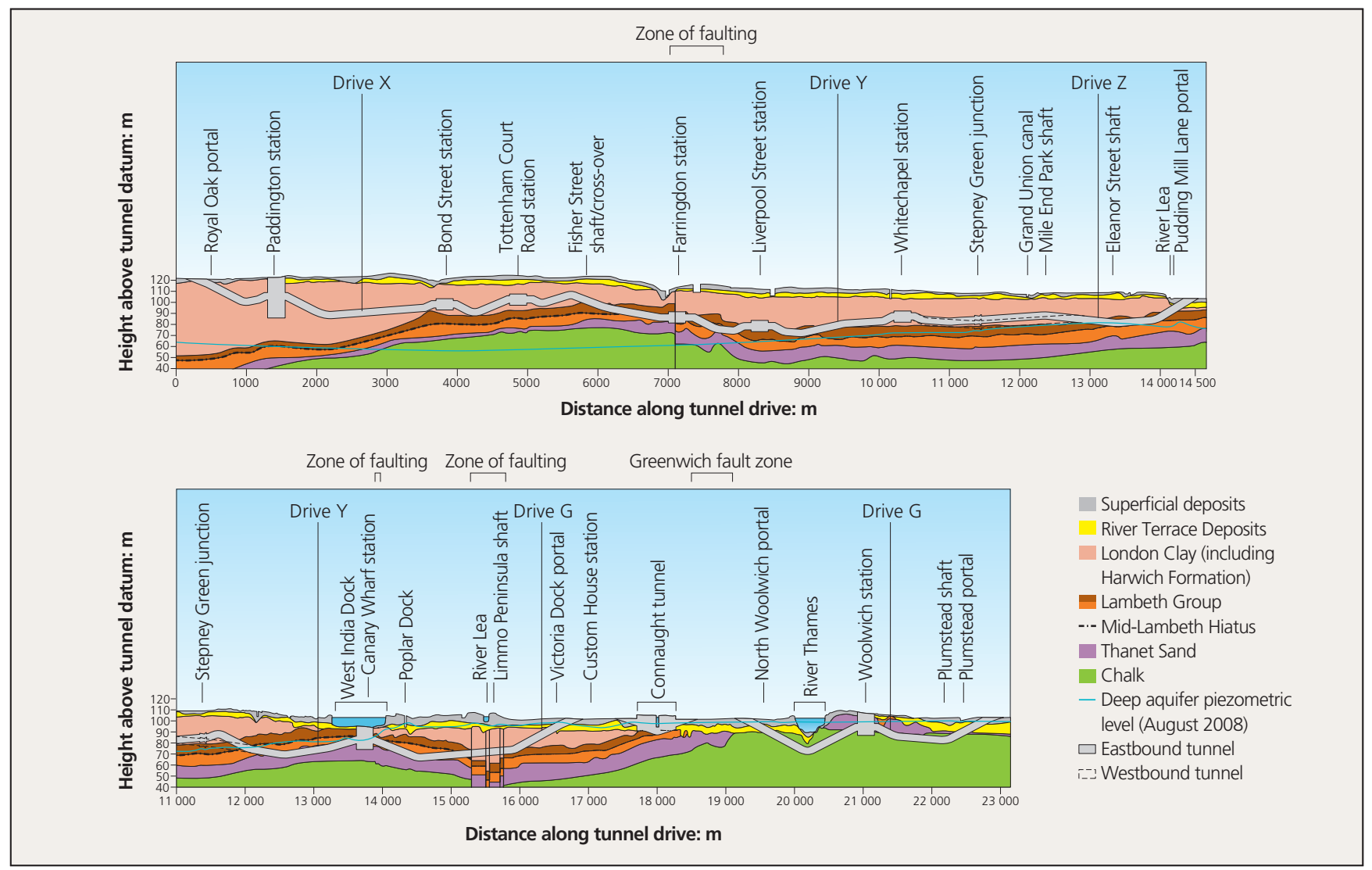

Figure 2. Geological long-sections of tunnel drives

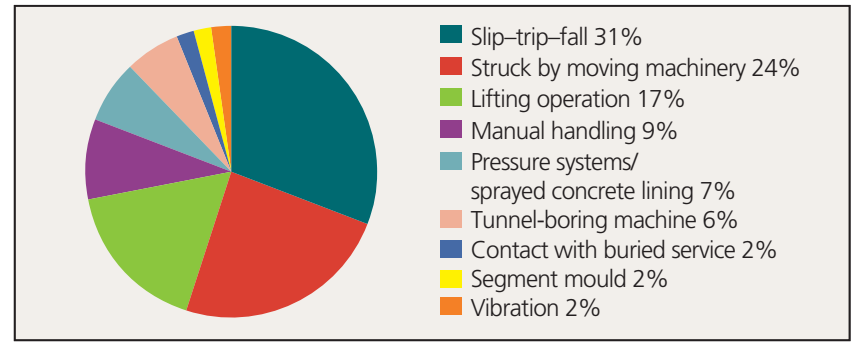

Figure 3. Breakdown of tunnelling incident categories

\section{Lining design}

The bored tunnel ground support was developed as a precast segmental lining, to be installed using TBMs. The lining design had to ensure that the project requirement for a 120 year design life was met, together with stringent requirements for the performance of the tunnel lining in the event of a fire. For this design case, the tunnel linings were required to continue to support the ground and the surrounding assets, but with a reduced overall factor of safety until any repairs could be undertaken as necessary.

A major exercise was undertaken early in the design to space proof the bored tunnels to ensure that adequate provision was made for the railway, track form, evacuation and emergency walkways and to accommodate the necessary in-tunnel systems and services (Figure 4).

The excavated diameter of the tunnels was approximately $7 \cdot 1 \mathrm{~m}$, allowing a $6.2 \mathrm{~m}$ internal diameter $(6.8 \mathrm{~m}$ external diameter) precast concrete segmental lining to be erected, with the annulus between lining and ground filled with grout injected through the TBM skin.

The tunnel lining comprised seven segments plus a small key (see Figure 5) and had a nominal length of $1.6 \mathrm{~m}$, with a taper across the diameter to aid with alignment control without compromising the water-proofing system. Sealing against groundwater pressures of up to 4 bar was achieved using composite ethylene-propylenediene-monomer (EPDM)/hydrophilic gaskets on every segment, except in the west section of drive X through the London Clay, where a standard EPDM gasket was used.

Where TBMs were used to build pilot tunnels, for example through station areas, $1 \mathrm{~m}$ long rings were used. This aligned with the $1 \mathrm{~m}$ advance lengths to be used for the sprayed concrete lining (SCL) enlargements to full platform tunnel size.

The $300 \mathrm{~mm}$ thick segments were steel-fibre reinforced using grade $\mathrm{C} 50 / 60$ concrete, with additional bar reinforcement only being used for certain extreme load cases. These cases were associated with proximity to existing adjacent structure foundations, and beneath sections of the floating track slab sections of the track, where it was necessary to provide improved shear resistance from the track slab loading points onto the tunnel lining. 
Crossrail project: machine-driven tunnels on the Elizabeth line, London

King, Thomas and Stenning

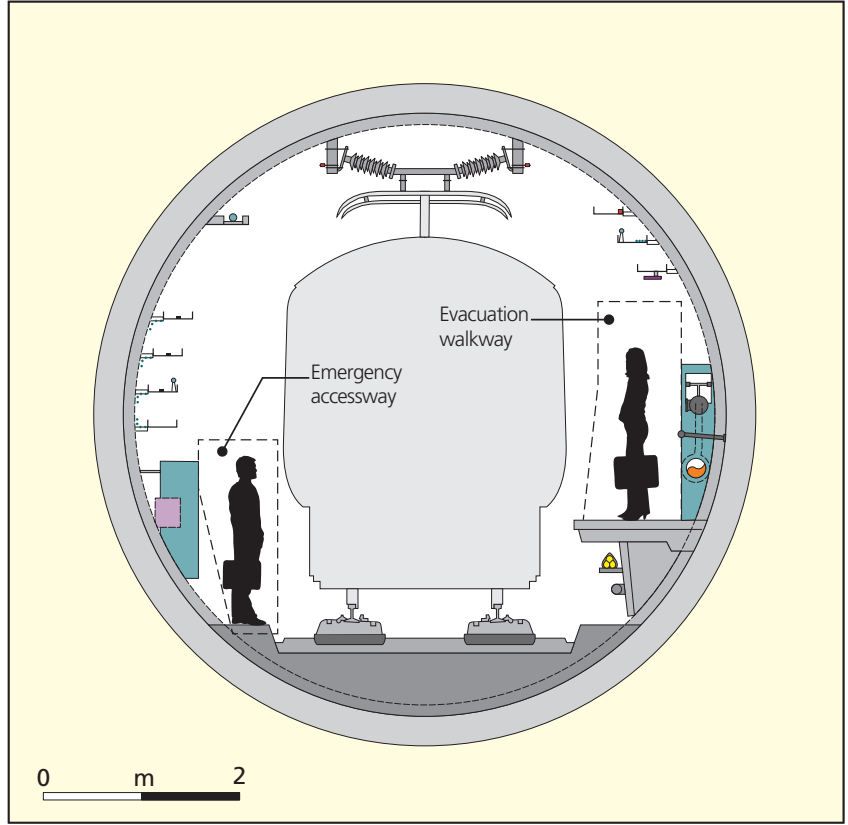

Figure 4. Cross-section of typical bored running tunnel

The segments were erected into a ring using vacuum erectors on the TBMs. During erection, two angled steel bolts across the longitudinal joints were inserted into cast-in sockets, although the bolts were removed from the lining above axis later to mitigate against the risk of a bolt becoming loose and detached during normal train operations. Each segment also had three dowels across the circumferential joint, except for the key segment which only had one.

The specification required that keys were not to be placed below the axis of the tunnel, partly to avoid starting ring build above axis, and partly due to track loading issues on the keys, particularly where floating track slab was required. Left taper and right taper rings were used to meet these objectives, and slightly different tapers were used on the different drives to suit the minimum horizontal curves on each contract - see Figure 6 for a completed section of tunnel.

Each segment was cast with at least one blind grout hole in the centre of the segment to locate the lifting vacuum plate of the TBM erector, and for any secondary grouting required.

The project observed more cracking in the steel-fibre-reinforced concrete (SFRC) segments than was originally expected, although no definitive root cause was established. The cracking was minor and generally self-healed, although some crack injection was carried out where minor leaks were observed or where cracks were over $0.3 \mathrm{~mm}$.

In conclusion, approximately $2 \%$ of segments built showed some degree of cracking. The cracking occurred in the weakest area of the segment, for example over fixing bolts or dowels, and was often seen to be associated with TBM steering on the tighter horizontal and vertical curves.

\section{Cross-passages}

To make provision for safe evacuation from the running tunnels and to enable emergency intervention, cross-passages were

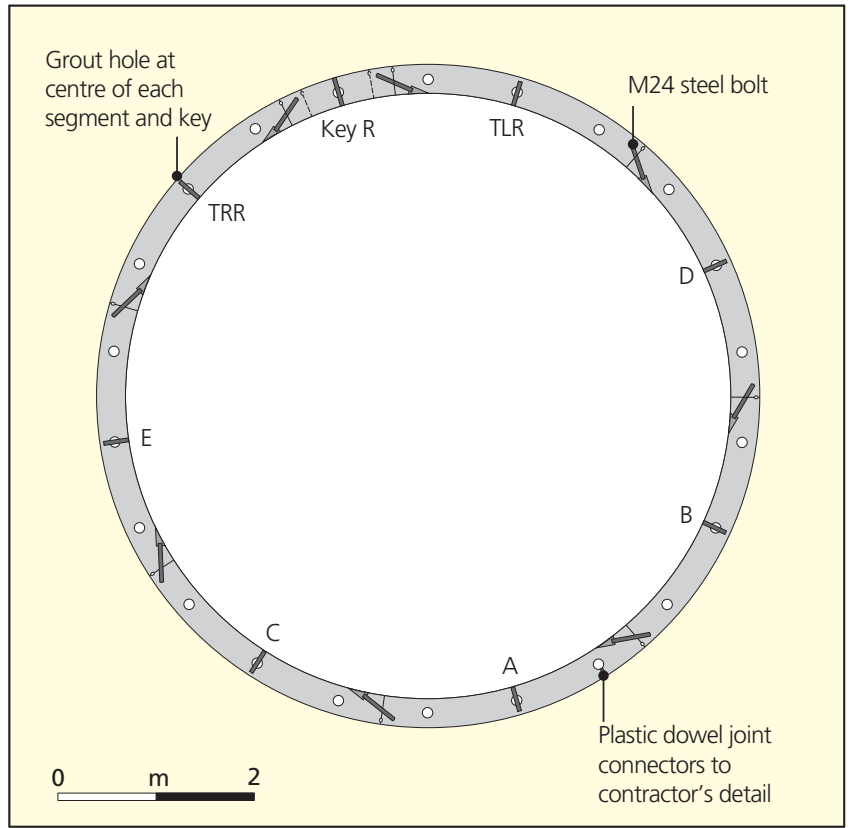

Figure 5. General arrangement of precast concrete tunnel ring

required at approximately $500 \mathrm{~m}$ intervals and were constructed either in spheroidal graphite cast iron (SGI) or SCL for primary and secondary linings to suit ground conditions.

The openings from the main tunnels were generally formed using hybrid concrete/SGI rings, except on C310 drive H, where more temporary support within the tunnel was used to support the concrete rings until the permanent structural reinforced concrete could be cast at the junction. $\mathrm{C} 310$ also used a combination of SCL primary lining, sheet membranes and cast in situ concrete secondary linings within the cross-passages.

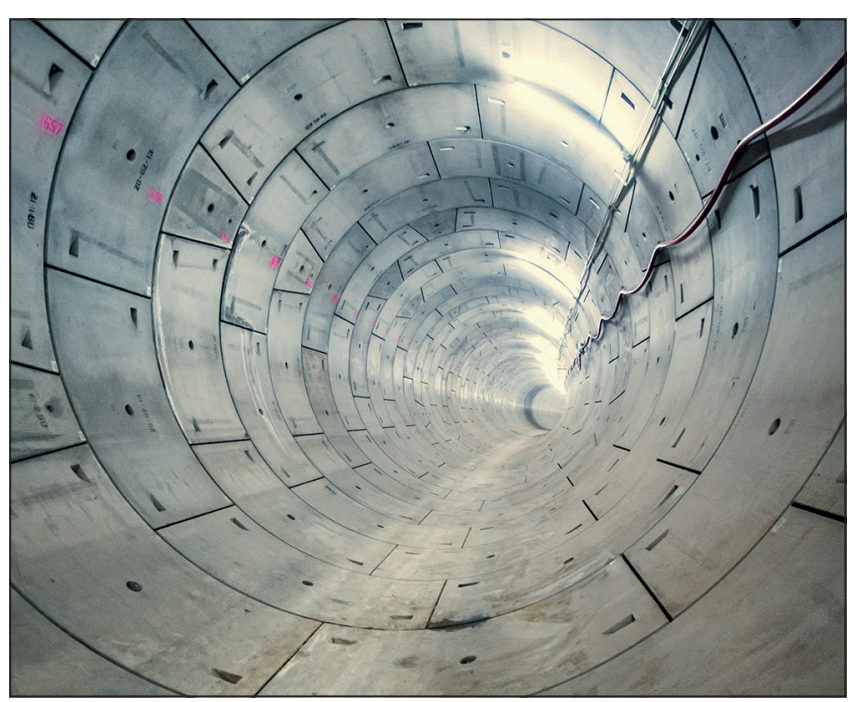

Figure 6. Completed section of segmentally lined running tunnel 


\section{Settlement and ground movement assessment}

There were over 17500 third-party assets with the potential to be impacted by the Crossrail works through central London. Each asset had to be assessed in terms of the impacts of the predicted ground movement to ensure the impacts were managed within acceptable limits, and that, where necessary, mitigation measures were developed and implemented to ensure all third-party assets remained serviceable throughout the construction of the project.

The assets comprised overground structures $(2 \%)$, buildings $(18 \%)$, heritage structures $(4 \%)$, underground structures $(2 \%)$ and utilities $(74 \%)$. The approach to the prediction of ground movement and the assessment of impacts followed the well-tested and understood Gaussian curve empirical methods for bored tunnels, with two- and three-dimensional finite-element analysis being employed adjacent to complex station locations to create a combined ground movement model, which could be used to assess the level of impact on all the adjacent assets.

Generally, $1 \cdot 0 \%$ volume loss was specified for the TBM running tunnels. In areas particularly sensitive to the effects of ground movement along the bored tunnel alignment, volume loss control measures were defined within the construction contracts. Typically, control zones of $0.5 \%$ or $0.75 \%$ volume loss were specified to control movements at source and avoid any adverse impacts and minimise the requirement for intrusive mitigation works.

The whole process of identifying the assets affected, obtaining information, predicting ground movements, assessing impacts, liaising with numerous interested third parties, agreeing impacts, designing and agreeing instrumentation and monitoring, and developing action plans and requirements for mitigation measures was a major undertaking over many years of design development prior to construction and also during the whole construction phase. The whole process comprised one of the most extensive ground movement prediction and damage assessment exercises that has ever been undertaken.

Given the number, sensitivity and historic significance of some of the assets, a systematic approach had to be developed for the project. This provided a structured, progressive, settlement prediction and ground movement impact assessment methodology which could be applied to the variety of different types of buildings, above- and below-ground structures and utilities.

For buildings there were two parts to the assessment. The first comprised the engineering-based damage category derived from the magnitude of predicted ground movement, type of foundation and type of building, yielding calculated strains in the superstructure. The second part, for listed buildings, assessed an additional heritage score, considering the heritage sensitivity of the structure and any special features and finishes. The damage category and heritage score were added to assign a total score to each listed building. The damage category or total score was used in assessing the need for mitigation measures.

A widespread array of instrumentation was installed along the alignment to monitor the buildings, structures and utilities within the zone of influence of the works. A series of monitoring trigger levels were defined for each asset, comprising green, amber and red triggers, reflecting the predicted movement and how much the structures could tolerate without significant damage. Overall, the actual movements were generally less than predicted, reflecting the purposely conservative methodology adopted for settlement calculation and damage assessment.

\section{Alignment and survey control}

The survey was carried out on the London grid, a system that is widely adopted in London for infrastructure projects and particularly for underground projects.

The TBM survey was run as an open traverse from the launch area as a 'zig-zag' across the tunnel in the upper quadrants of the tunnel. Instrumentation was specified by the client team as total station with an accuracy of 1 second or better and $1 \mathrm{~mm}+1.5$ parts per million.

Programming circumstances in the west, in particular, meant that anticipated hole-throughs into the tunnel for survey closure were not made, and the consequent open traverses were longer than expected. As a result, the ellipse of error in the survey grew beyond that which had been originally envisaged.

The drive tolerance of the TBM was $50 \mathrm{~mm}$ from the theoretical alignment in any direction. On the whole the drive tolerances, as defined by the alignment information available at the TBM, were met, other than in a few areas where tight curves and chicanes were being negotiated with temporary linings.

However, during the wriggle survey, after the TBMs were removed and alignment could be run from open ends of the tunnels, it was found that longer sections of alignment were out of tolerance by more than had originally been identified after correction of the survey ellipse of error.

In most cases between stations this tunnel misalignment could be taken up by minor realignment of the track along with some additional reinforcement; however, at Tottenham Court Road station platform in particular, some rework of the design was necessary within the station platform tunnels to achieve the required clearances with a revised alignment.

\section{Tunnel spoil transportation and disposal strategy}

To minimise environmental impact Crossrail gave an undertaking to make beneficial reuse of the tunnel excavated material wherever possible and set a target of $95 \%$ reuse across the whole project, achieving a level of $99 \%$ for the TBM excavated material.

Most of the TBM drive sites, with the exception of drive $\mathrm{H}$ site at Plumstead, were located within busy areas of London and consequently the project also wanted to maximise the use of rail and water transportation systems, such that it could minimise lorry movements, particularly from the main TBM sites.

Wallasea Island in the Thames estuary was identified as the main destination for the majority of the TBM-excavated material. It has resulted in constructing Europe's largest artificial bird sanctuary approximately $13 \mathrm{~km}$ north of Southend-on-Sea on the River Crouch. Other destinations were also used and the main sites are noted below, although numerous other, smaller sites were also used, such as donations to inner city farms.

The excavated material from the TBM drives was classified under two main types based on the machine type used, which determined its eventual use. 
Slurry TBM-excavated material from drive $\mathrm{H}$ consisted of a mixture of excavated material (mainly Chalk, Thanet Sand and Lambeth Group Formation), water and bentonite. The material was considered to be unsuitable for transportation by ship and was therefore not used at Wallasea and was transported to licensed waste recovery and landscaping disposal sites. The majority of this material was transported by road to east Tilbury quarry landfill site, and Pitsea.

EPBM-excavated material from drives $\mathrm{X}, \mathrm{Y}, \mathrm{Z}$ and $\mathrm{G}$ was mainly from the London Clay for the drives from the west, and a combination of London Clay and Lambeth Group Formation for the drives from the east. The material was conditioned at the face using a variety of water, air and conditioners. The material was generally suitable for transportation by train and ship and the vast majority of the material was sent to Wallasea Island. Material was transported from the TBM to the surface by conveyors.

In-tunnel transportation of spoil was by conveyor on the EPBM drives and pumped spoil lines on the slurry drives. London Clay provided a challenge for all the conveyor suppliers due to its ability to clog and stick in transit to all surfaces. As a consequence, all of the conveyors suffered from failures in service to a lesser or greater degree.

The transportation methods used from the main construction sites to the final disposal sites differed for the main drive sites constructing tunnel drives under sections $\mathrm{X}, \mathrm{Y}, \mathrm{Z}$ and $\mathrm{G}$ of the alignment.

From the drive $\mathrm{X}$ worksite at Royal Oak Portal, the material was transported by train to a main storage facility at Northfleet Wharf in Kent. From here, the material was transported by ship to Wallasea Island.

From drives $\mathrm{Y}$ and $\mathrm{G}$ worksite at Limmo peninsula, a conveyor system was used to transfer the material directly to Instone Wharf and it was then transported by ship to Wallasea Island. When the material was deemed to be too wet to transfer by ship safely, it was moved by road to Ingrebourne landfill site or by barge to Goshams Farm, where the material was used for restoration and landscaping.

Drive $\mathrm{Z}$ worksite at Pudding Mill Lane had no direct access to rail or water transportation systems and the material was transferred by road to a transfer site at Barking. The material was shipped to Wallasea from there.

\section{TBM specification and procurement}

The Crossrail client team specified minimum requirements for the TBMs, with procurement and ownership as the responsibility of the main contractors.

All TBMs supplied to Crossrail were supplied by a single TBM supplier. This was not a policy set by either the client organisation or the main contractors as all TBM supply contracts were tendered competitively and separately.

\section{Special features of TBM design}

Because of the single source supply for the TBMs, all followed a basic pattern that was set by the procurement of the first machines, those of the drive $\mathrm{X}$ contractor.

To promote the movement of excavated ground through the cutter-head, the machines were designed with open cutter-heads.
This design was an iterative process and provided a cutter-head on the EPBMs with an opening ratio of $55 \%$. All the EPBMs on the project were then supplied with the same basic cutter-head arrangement (see Figure 7). It is impossible to quantify the benefit that the open-head brought to tunnelling effort; however, the cutter-heads performed well and there was little wear or excessive clogging.

The Crossrail TBMs were the first working TBMs in the UK to be equipped with refuges to BS 6164 (BSI, 2011). The key features of these refuges were

- capacity: 20 people

- protection against smoke by positive pressure and air conditioning

- breathable air supplied from the surface as well as air cylinders and emergency oxygen canisters in the refuge to stand alone for $24 \mathrm{~h}$ should the surface air supply fail

- communication link to the surface.

The routing of the running tunnels ran underneath some of the world's most expensive property and infrastructure, and as a result demonstrable control of the TBMs to reduce surface settlement was of great importance.

The machines were operated to control ground movement in the usual manner by control of face pressure and grout pressure and volume, with limited use of bentonite around the shield annulus if circumstances allowed.

To demonstrate control, all EPBMs were fitted with two highly accurate and independent belt-weighers on the primary belt conveyor. The accuracy of the belt-weighers was specified at $0.5 \%$ maximum error in service. Two belt-weighers were incorporated to provide checks and balances on each other, and the data from them, along with all other TBM data, were transferred back to the surface control rooms.

The belt-weighers required daily cleaning to ensure that accurate results were being provided to the control room. Modifications were made to the guarding to the belt-weighing stations to ensure the health and safety of those operatives involved in the cleaning operation. These modifications all centred on providing demountable guarding to the weighing stations and ensuring that

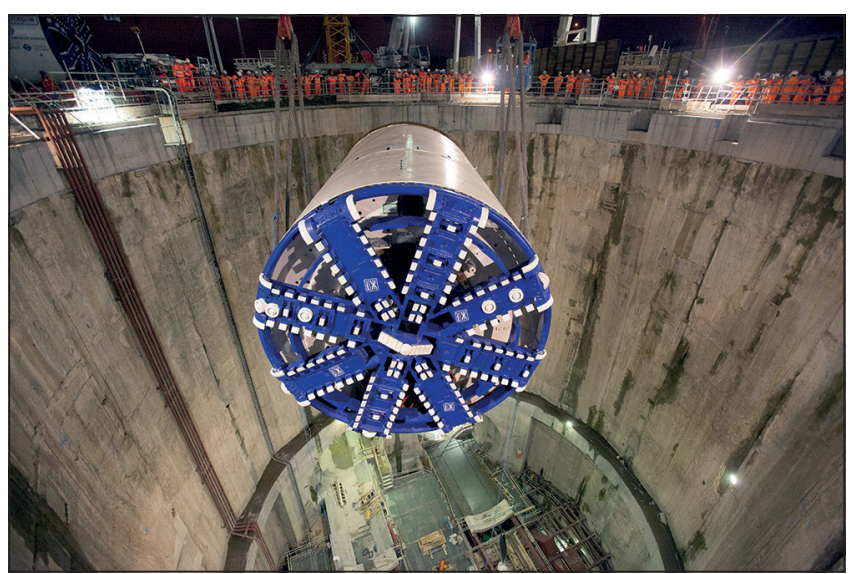

Figure 7. TBM cutter-head 
Civil Engineering

Volume 170 Issue CE5
Crossrail project: machine-driven tunnels

on the Elizabeth line, London

King, Thomas and Stenning a robust interface was in place to ensure that, if the guards were removed, the belt was prevented from running.

As typically seen with machines this size, they were relatively confined, and ventilation, particularly to the upper deck of the back-up train, was troublesome. The passage of fresh air was often blocked and diverted by the inherent TBM structure. As a result, some of the upper deck workstations suffered from poor ventilation. Modifications were made to the TBM ventilation during construction to improve this situation.

\section{TBM productivity}

Table 3 summarises some of the key production figures for the different contracts - note that advance rates are provided as rings/d, with some contracts using short sections of $1 \mathrm{~m}$ long temporary rings.

Drives $\mathrm{Z}$ and $\mathrm{G}$ showed higher productivity generally than the longer drives, but they were short drives, mined by teams who had already worked together on previous Crossrail drives and who had already been through the learning curve.

\section{Launching of TBMs}

The three TBM contractors adopted different means of TBM assembly and launch to suit the constraints of their sites.

In the west at Westbourne Park, the two drive X TBMs were assembled in the widest part of the site some $600 \mathrm{~m}$ from the tunnel launch eye at the portal face. The reasons for this were that the proximity of Networks Rail's Great Western line and the London Underground Hammersmith and City line to the launch eye meant that the management of heavy lifts would be troublesome in this location.

To mitigate the risk, the contractor selected to assemble and commission both TBMs away from the launch eye in a factorystyle environment and transport them to the launch site using selfpropelled modular transporters. The launch was then carried out using a standard launch frame, temporary launch rings and sealed eye arrangement (Figure 8).

In the east at Limmo site for drives $\mathrm{Y}$ and $\mathrm{G}$, the two TBMs were assembled on the surface as shields only and lowered to the base of the shaft as single units. From there the machines were shoved forward on greased launch rails to the launch eye in a short SCL launch tunnel and the back-up was assembled and commissioned behind the shields. The launch was carried out using a circular shove frame that had been cast into the shotcrete tunnel incorporating a sealed eye arrangement.

At Plumstead portal the TBMs were assembled and commissioned in the portal immediately outside the launch eye. The machines were launched using the 'flying launch system'. This is a system that relies on the installation of a pressure ring immediately behind the shields, which is tied to the portal eye using a number of tension bars (Figure 9). The shields are pulled forward into the ground through the eye-seal system by using hydraulic jacks pulling on the tension bars. The TBM propulsion rams bear against the pressure ring but do not propel the machine forward until the machine is launched. This system does away with the need for temporary launch rings.

\section{Reception of TBMs}

Reception of TBMs was in most cases relatively straightforward and only the exceptions will be mentioned here.

The reception arrangements for drives $\mathrm{X}$ and $\mathrm{Y}$ were modified to suit other construction and programme activities. As the complexity of the construction at Farringdon station developed, it became clear that TBM removal would not be possible with lifting access from directly above. To overcome this, the drive X TBMs were driven on tight curves off to the side at the ends of the platform tunnel pilot lengths, away from the twin bores and the shields stripped down where possible, and concreted in place. The back-up trains for the

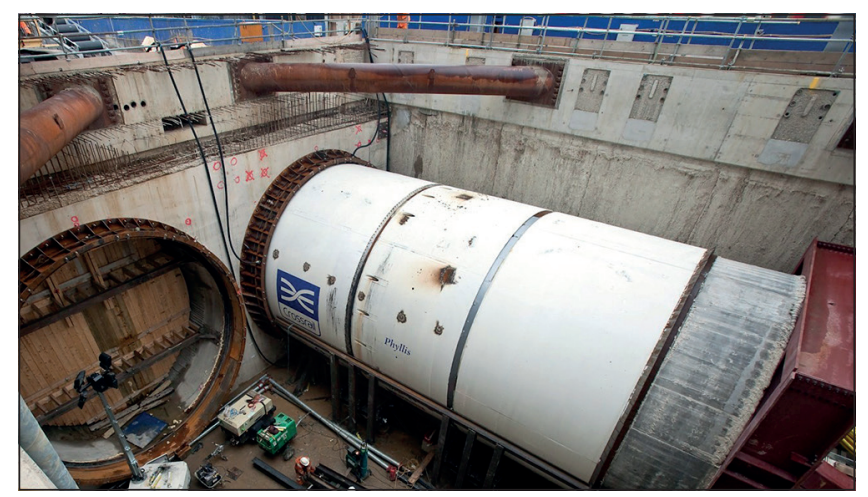

Figure 8. Drive X TBM launch on C300

Table 3. TBM production figures

\begin{tabular}{|c|c|c|c|c|c|c|c|c|c|c|}
\hline TBM & Phyllis & Ada & Elizabeth & Victoria & Sophie & Mary & Ellie & Jessica & Ellie & Jessica \\
\hline Drive & $x$ & $x$ & Y & Y & $\mathrm{H}$ & $\mathrm{H}$ & Z & Z & G & G \\
\hline Total tunnelling time: $d$ & 519 & 522 & 896 & 895 & 392 & 367 & 127 & 172 & 69 & 42 \\
\hline Tunnelling time excluding delays: $d$ & 358 & 313 & 362 & 402 & 217 & 171 & 94 & 99 & 39 & 33 \\
\hline Average progress including delays: rings/d & $9 \cdot 0$ & $8 \cdot 9$ & $5 \cdot 1$ & $5 \cdot 5$ & $4 \cdot 4$ & $4 \cdot 6$ & $13 \cdot 9$ & $9 \cdot 8$ & $7 \cdot 6$ & $12 \cdot 4$ \\
\hline Average progress excluding delays: rings/d & $13 \cdot 1$ & $14 \cdot 9$ & $12 \cdot 5$ & $12 \cdot 3$ & $7 \cdot 9$ & $10 \cdot 0$ & $18 \cdot 7$ & $17 \cdot 0$ & $13 \cdot 4$ & $15 \cdot 7$ \\
\hline Maximum progress: m/d & $52 \cdot 8$ & $48 \cdot 0$ & $68 \cdot 8$ & $94 \cdot 4$ & $25 \cdot 6$ & $27 \cdot 2$ & $72 \cdot 0$ & $48 \cdot 0$ & $46 \cdot 4$ & $43 \cdot 2$ \\
\hline Maximum progress: rings/d & 33 & 38 & 43 & 59 & 16 & 17 & 45 & 30 & 29 & 27 \\
\hline Maximum progress: rings/week & 179 & 185 & 169 & 216 & 91 & 100 & 186 & 127 & 159 & 159 \\
\hline
\end{tabular}




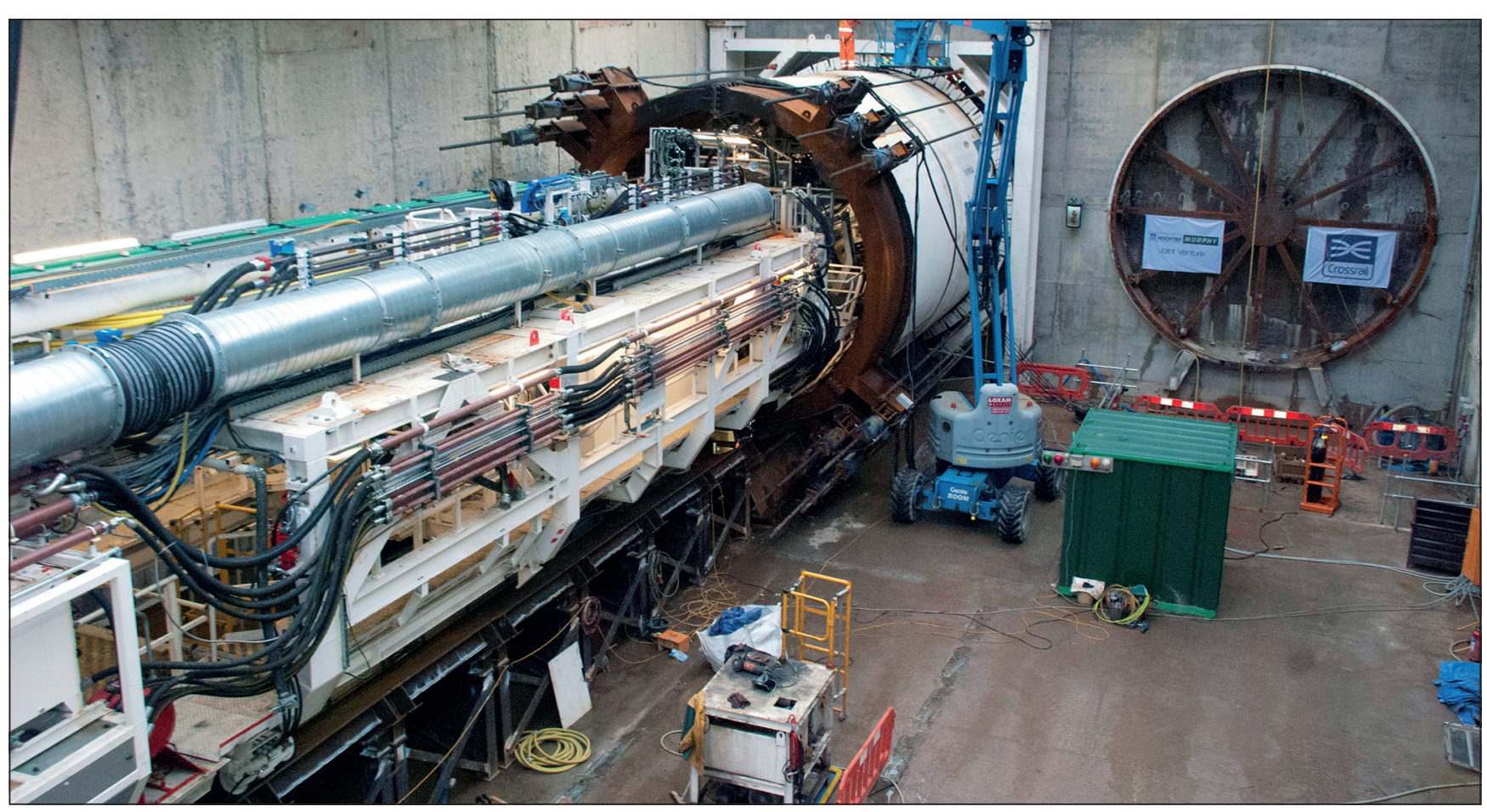

Figure 9. Drive H TBM launch on C310

drive X TBMs were stripped and hauled backwards to be removed from the working shaft at the Fisher Street crossover.

The drive Y TBMs were driven into the eastern end of Farringdon Station, where platform enlargements had been constructed, and were then stripped and dismantled underground, with back-up and shield contents removed backwards through the completed drive $\mathrm{Y}$ tunnels.

Neither arrangement was considered optimal as stripping machines backwards is time consuming compared with the usual reception pit arrangement, where TBM components can be lifted out directly. Also, significant amounts of underground cutting and burning were required during the dismantling process, adding to the health and safety hazards.

\section{Lessons learnt and legacy}

Some of the lessons learnt on the TBM drives for this project to be carried forward to the next scheme are as follows.

There needs to be some contingency in defining space for the works, including space-proofing inside the tunnel, at the planning stage to allow flexibility for further design development and optimisation.

To minimise obstruction risk, significant effort is required for route validation - obtaining clear and consistent information relating to existing buildings, structures and assets.

Ground movement prediction and assessment of impacts was a major undertaking given the location, number of assets, the asset sensitivity, age, condition and importance, and the numerous third parties to interface with. This was successfully achieved using a logical process and through continuous liaison with third-party owners.
Care should be taken in TBM design to ensure ventilation is adequate to all work stations on the TBM, taking into account potential shadowing of larger items of plant on the back-up.

TBM reception arrangements at Farringdon were not ideal. To reduce the health and safety risk and programme risk of TBM assembly and disassembly in confined space, appropriate time and space should be secured for TBM reception arrangements.

Design tolerances and space-proofing of the tunnel alignment should take full account of the ellipse of survey error imposed by the accuracy of survey instruments and limits in sight lines over the full length of the drive, particularly where survey closure is not possible for long tunnel lengths.

To drive innovation in TBM supply, the constructing teams should consider promoting a diversity of TBM supply as has been the case on previous UK multi-TBM projects.

Finally, the conveyor systems suffered from several failures, including structural issues. Conveyor designers must be made aware of the clogging potential of London Clay and their design scrutinised by suitable category three checkers. The conveyor designer should be asked to provide recommendations for planned preventative maintenance of the system and all its components.

\section{References}

Black M (2017) Crossrail project: managing geotechnical risk on London's Elizabeth line. Proceedings of the Institution of Civil Engineers - Civil Engineering, http://dx.doi.org/10.1680/jcien.16.00024.

BSI (2011) BS 6164:2011: Code of practice for health and safety in tunnelling in the construction industry. BSI, London, UK.

Tucker W (2017) Crossrail project: the execution strategy for delivering London's Elizabeth line. Proceedings of the Institution of Civil Engineers Civil Engineering, http://dx.doi.org/10.1680/jcien.16.00021. 